\title{
Valparaíso: su geografía, su historia y su identidad como Patrimonio de la Humanidad
}

\section{Valparaiso: geography, history and identity of a town that belongs to the patrimony of humankind}

\author{
Alfredo Sánchez M.*, Joaquín Bosque M.**, Cecilia Jiménez V.***
}

\section{INTRODUCCIÓN}

La ciudad de Valparaíso es una de las más antiguas del país. Su privilegiada situación facilitó la formación de una identidad local, construida a partir de la relación hombre con el entorno natural, donde se distinguen tres componentes: la bahía, el plan y los cerros. Desde su origen fue definida a partir de dos factores que a través del tiempo fueron determinando su perfil. Estos fueron, su carácter urbano y la actividad portuaria, por lo que puede decirse que desde su nacimiento se fue estructurando en torno a la dualidad de ser conjuntamente ciudad-puerto.

Su historia comienza en 1536, cuando don Diego de Almagro realiza la primera expedición desde el Perú hacia Chile, el capitán don Juan de Saavedra, un subalterno que lo acompañaba en la expedición a través del Océano Pacífico, fue el primero en descubrir la bahía de Alimapu en la que desembocaba el valle de Quintil, donde hoy día se ubica la Plaza Echaurren, nombre que destacaba por la vegetación que originalmente rodeaba el sector.

El crecimiento de la ciudad se estructuró a partir de las características naturales de su emplazamiento, mientras la arquitectura colonial española pro-

\footnotetext{
* Alfredo Sánchez M., Instituto de Geografía, Pontificia Universidad Católica de Chile.

** Joaquín Bosque M., Real Sociedad Geográfica.

*** Cecilia Jiménez V., Facultad de Arquitectura, Universidad de Valparaíso, Chile.
} 
pia de las ciudades chilenas, se adapta a las condiciones naturales del sitio de Valparaíso y se mezcla con la arquitectura europea de corte victoriano, como herencia de los inmigrantes británicos y también alemanes que llegaron a sus costas durante el siglo XIX.

El período de mayor esplendor poblacional y económico fue durante el siglo XIX, como un importante enclave dentro de las rutas que comunicaban Europa con la costa del Océano Pacífico a través del Cabo de Hornos. El puerto se transformó en el punto de entrada y salida de mercaderías de toda la zona central del país. Entre 1810 y 1822, la población de la ciudad aumentó de 5.500 a 16.000 habitantes, con una población flotante de más 3.000 marinos nacionales y extranjeros, transformándose en la segunda ciudad del país.

Su gran actividad portuaria y mercantil dentro del plano del desarrollo nacional, Valparaíso fue el eje de la capital económica del país, ahí nacieron los bancos, las compañías navieras, las compañías exportadoras, concentrando el mayor movimiento monetario, la mayoría de las sedes de las nuevas sociedades mineras e industriales, oficina de ferrocarriles, compañías mercantiles y aseguradoras tuvieron sus casas matrices en la ciudad de Valparaíso.

La presencia del puerto ha facilitado también la importación y exportación de mercaderías, y en la perspectiva actual, bajo el proceso de integración regional del continente, Valparaíso aparece como la puerta de salida del futuro corredor bioceánico. Mientras que el entorno urbano aporta el apoyo necesario a la actividad portuaria con el desarrollo de una completa infraestructura vial.

Desde su privatización el puerto Valparaíso ha registrado un fuerte crecimiento en la transferencia de carga, lo cual hace necesario su expansión física, mediante áreas de respaldo para sus actividades. En la actualidad su economía se caracteriza por la presencia de un sector empresarial moderno, formado por empresas más bien de tamaño mediano y grande, donde se observa una alta concentración de capitales, altos niveles de tecnología y sistemas de gestión, con un énfasis en el mejoramiento sostenido de la productividad y de la competitividad, y donde la producción se orienta a mercados externos.

Entre los factores que conforman el patrimonio, parece fundamental resaltar su aspecto geográfico que sirvió de base en la decisión de la Organización de las Naciones Unidas para la Educación, la Ciencia y la Cultura (UNESCO), de declarar a la ciudad de Valparaíso como Patrimonio de la Humanidad (2003). El privilegio de esta designación implica un reconocimiento oficial y universal de que este bien constituye una riqueza de gran significado para toda la humanidad, desde el punto de vista histórico urbano, arquitectónico, artístico, científico, estético, arqueológico y antropológico. 
ORIGEN, IMPORTANCIA Y DESARROLLO DE LA CIUDAD

\section{Localización y entorno geográfico natural}

La ciudad cuenta con una población de unos 300.000 habitantes. Forma junto con Viña del Mar una conurbación adquiriendo la fisonomía de una ciudad cosmopolita. Nació como ciudad puerto y en consecuencia su desarrollo urbano ha estado esencialmente condicionado por esta actividad. Su privilegiada situación le permitió en el plano histórico tener una fuerte presencia en el proceso fundacional de las nuevas tierras otorgadas por Don Pedro de Valdivia al Rey de España. Su historia se inicia en el año 1536, durante la primera expedición de don Juan de Saavedra a las costas el Océano Pacífico. En 1544, Valdivia declara a Valparaíso como puerto de Santiago. El nombre original de su emplazamiento era el Valle del Paraíso, debido a la admiración que provocaban los encantos naturales de la región a los navegantes que provenían de otras latitudes.

La ciudad de Valparaíso está emplazada sobre una antigua playa de arena cubierta por relleno artificial, y su proceso de expansión urbana se ha logrado ganado terreno al mar. Especial mención merece el caso del sector Almendral, que siendo originalmente una playa, se consolidó más tarde, después de un proceso de relleno, como una parte importante del plan de la ciudad. En este mismo sentido hay que hacer mención a la ocupación gradual de las quebradas y terrazas marinas ascendentes, es decir, los cerros que rodean la bahía de oeste a este.

Desde el punto de vista físico-geográfico, la ciudad de Valparaíso se encuentra emplazada en medio de una planicie costera en dirección norte-sur. Por su condición geográfica y su localización se define como una ciudad puerto de la costa suroeste de América del Sur entre las coordenadas de latitud $33^{\circ} 01^{\prime}$ sur y longitud $71^{\circ} 38^{\prime}$ oeste y a unos $118 \mathrm{Kms}$ al noroeste de la ciudad capital de Santiago. Tiene una identidad propia, cuyo mayor símbolo es su entorno natural, compuesto por una bahía rodeada de una cadena montañosa de tipo cordillerano que baña sus faldas en el mar y que la convierte en un anfiteatro que mira hacia el Océano Pacífico (figura 1).

En la descripción histórica del sitio de Valparaíso el componente geográfico ha sido siempre muy destacado en el análisis histórico, como ocurre con las narración que describen una vegetación natural con interesantes variedad de especies, las que ocupaban cerros y quebradas. En realidad, Valparaíso dispuso en sus orígenes de un bosque nativo esclerófilo exuberante que fue una condición básica para el desarrollo del asentamiento poblacional, el recurso 


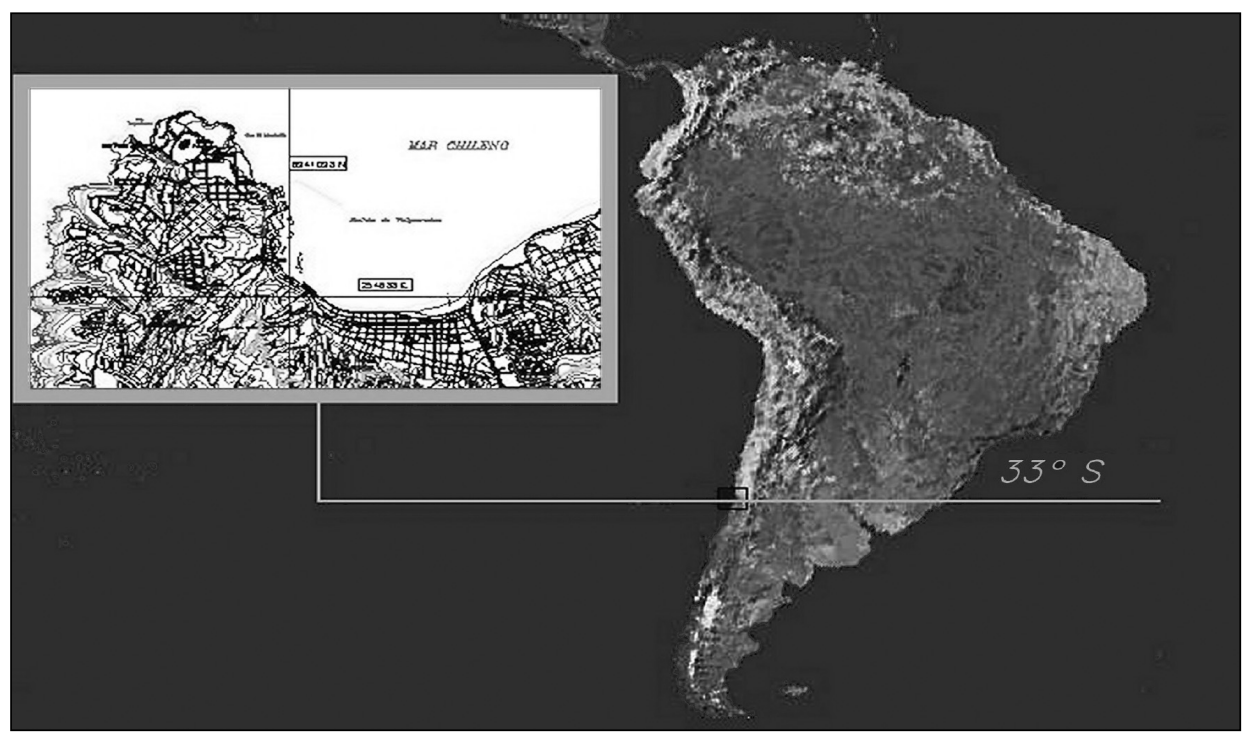

Fuente: I. Municipalidad de Valparaíso, 2003, Unidad Técnica del Patrimonio.

FIGURA 1. Valparaíso a escala continental

energético. Las especies autóctonas como: Litre, Boldo, Peumo, Pataguas, Arrayán, Quillay coexistían con unidades de palmas chilenas (Jubaea Chilensis), un paisaje sobre el cual se sustenta el topónimo de Valparaíso.

En cuanto a sus condiciones climáticas los cursos naturales de agua que desde el cerro bajan al sector plano de la ciudad son abastecidos sólo por las precipitaciones, reduciéndose drásticamente su caudal en el verano. Su localización en un área de clima templado tipo mediterráneo, con lluvias invernales que, en promedio, ascienden a 480 milímetros anuales, concentrados principalmente entre los meses de mayo a octubre. La temperatura media en verano alcanza $20{ }^{\circ} \mathrm{C}$ y en invierno $15^{\circ} \mathrm{C}$. La variación media de temperatura entre máxima y mínima es de $5^{\circ} \mathrm{C}$. La humedad relativa del aire durante el día en el verano alcanza el $65 \%$.

Las favorables condiciones del clima con las cuatro estaciones del año bien diferenciadas hacen de su espacio, un lugar deseable para el asentamiento poblacional. Desde una perspectiva de la realidad nacional, la ciudad mantiene temperaturas moderadas a lo largo de todo el año, lo que se explica por la influencia de la corriente fría de Humboldt y de la brisa marina sobre el espacio costero local. Otro elemento geográfico propio de Valparaíso es el viento do- 
minante, que sopla desde el sur oeste alejando de la ciudad cualquier amenaza de contaminación del aire. Finalmente en términos de equilibrio ambiental, Valparaíso conserva aún en sus quebradas y zonas de la periferia urbana restos de aquella biodiversidad que lo caracterizo desde su fundación.

Un segundo aspecto relevante de su paisaje natural son sus acantilados, que se sitúan hacia el poniente de la ciudad y parecen ser única en el cono sur de América, a tal punto que fueron declaradas área protegida, como Santuario de la naturaleza por el Ministerio de Educación y el Consejo de Monumentos Nacionales. En efecto, de Valparaíso hacia el sur la costa se transforma en paisaje de acantilados siendo disectado por numerosas quebradas y esteros. El paisaje predominante muestra un ambiente relicto que destaca por albergar en pleno borde costero de Chile Central, especies propias de zonas más húmedas y de precordillera (Sánchez, A. y Morales, R., 2003).

La influencia del clima sobre Valparaíso adquiere su fase más crítica con los temporales de lluvia en la estación de invierno, los que coinciden con la generación de marejadas que vulneran el borde costero. Así mismo el escurrimiento de la aguas provoca desprendimientos de terreno sobre todo en las pendientes de las terrazas más altas afectando las construcciones y generando desprendimiento del suelo hacia las en zonas del plan. Esto ocurre cuando las precipitaciones son abundantes y continuas.

Única por su topografía, los componentes propios de este paisaje natural de la ciudad son: la bahía, el sector plan y sus cerros.

a) la bahía: ofrece un interesante aspecto natural, protegida por el sur, pero abierta a la dirección de los vientos y frentes del norte que en la estación de invierno golpean con fuerza a la ciudad. El borde mar como límite natural ha sido una dificultad constante al desarrollo urbano de la ciudad, desde su origen como caleta hasta la gran remodelación iniciada a partir de la privatización del puerto. Las distintas etapas de crecimiento van generando un impacto en la ciudad y van determinando la manera en la cual Valparaíso se relaciona con el mar.

La materialización de las obras de relleno para consolidar el borde costero se realizaron en varias etapas, identificándose en el período 1848 hasta 1885 como los más relevantes desde el punto de vista de inversión pública. Los rellenos, que en algún momento comenzaron a responder a necesidades productivas, fueron creando un borde costero desde Barón hasta Artillería, donde el muelle Prat es muy significativo, entre otras cosas, por ser uno de los puntos de mayor contacto entre la ciudad y el mar.

En la actualidad la necesidad de un mayor espacio sigue vigente. Donde se distinguen dos sectores portuarios: El Terminal Portuario Sur y en el extremo 
opuesto la zona de Barón, que era el puerto industrial donde llegaban las cargas como minerales, carbón y cargas relacionadas, siendo la principal utilidad del muelle la de abastecer carbón al desaparecido gasómetro. Hoy día, su entorno se encuentra en estudio con el llamado proyecto Barón, con una inversión de100 millones de dólares y que independiente de la forma como se materialice, la sustitución del uso industrial dará lugar a una nueva oportunidad de apertura hacia el mar (Hidalgo, R. 2005).

b) el plan: la estrecha planicie costera entre la bahía y los cerros, forman el sector plano de la ciudad. Se formó por el material proveniente de los cerros, y como ya se indicó, por las obras de relleno recuperando espacio al mar. Hay que mencionar también un tercer componente, los escombros provenientes de los movimientos sísmicos que han golpeado durante la construcción histórica de la ciudad. Este sector «Plan de la ciudad», como habitualmente se define, concentra más del $80 \%$ de las actividades productoras de bienes y servicios y menos del 5\% de la población comunal. Se divide en dos subsectores, definidos por su origen diferente y por la importancia adquirida a lo largo de la modernización de Valparaíso:

- El Almendral, su nombre recuerda la abundancia de Almendros, que en algún tiempo hubo en el sector, allí residen hoy, gran parte de los servicios públicos, el Congreso Nacional y empresas de Valparaíso y

- El Puerto, donde se sitúan bares, hoteles, actividades de servicios, como sedes bancarias, notarías; además de las instalaciones del puerto y el Servicio Nacional de Aduanas (figura 2).

El nuevo Plan asociado con su alta densidad de actividades económicas, como el valor del terreno más alto y un patrón de uso intensivo del espacio, representado por la presencia de grandes edificios antiguos y edificaciones en altura muestran una nueva cara a este sector de la ciudad. El plan de Valparaíso aparece hoy como un reflejo de las características propias de muchos centros urbanos de ciudades contemporáneas. El resto del sector plano, puede ser descrito en términos similares pero con menores índices de ocupación (Vásquez, N. 1999).

En el marco del proyecto Bicentenario nacional, el llamado "Plan Valparaíso" contiene variadas iniciativas, siendo la más reciente el "Programa de Recuperación y Desarrollo Urbano de Valparaíso"que terminará por favorecer el desarrollo del sector plan de la ciudad con un equilibrio entre modernidad y tradición. 


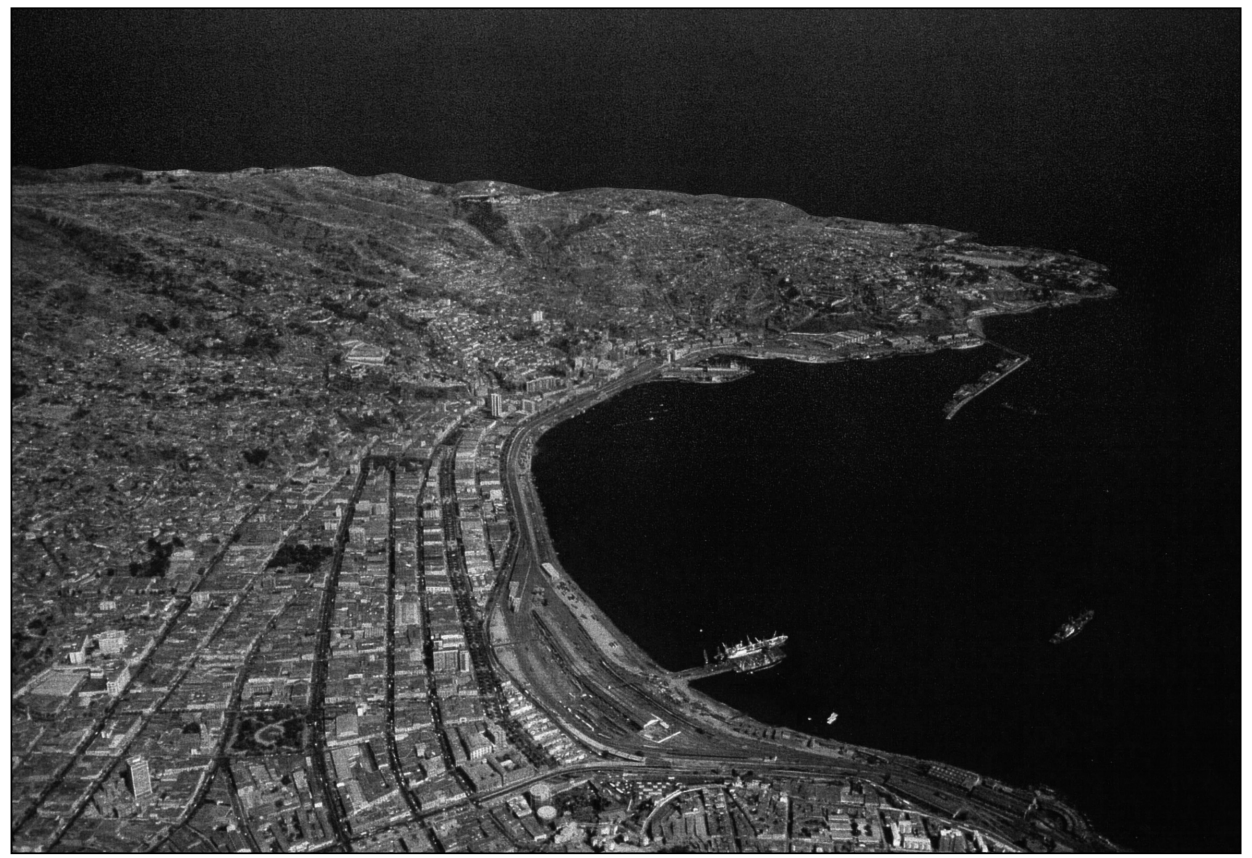

Fuente: Programa de Recuperación y Desarrollo Urbano de Valparaíso.

Figura 2. Componentes de la topografía de Valparaíso

c) los cerros: el anfiteatro de sus cerros aparece como uno de los mayores atractivos de la ciudad. Sus rasgos geomorfológicos más marcados son las terrazas de abrasión marina (formadas por acción erosiva del mar) y de depósitos (aquellos formados por material acarreado por cursos de agua que bajan desde la cima de los cerros). Las profundas quebradas que separan las terrazas forman los interfluvios, un vínculo entre el plan y cerro y son a la vez un puente de comunicación para la población que vive en el cerro y trabaja en el plan de la ciudad.

El frente de acantilados "muertos" ha constituido un elemento limitante para la expansión urbana de la ciudad, el que fue remediado con la presencia de los ascensores que unen el plan con el cerro y que forman parte de la identidad de la ciudad (Salinas, R. 1967). Mientras las quebradas con distintos niveles de pendiente han sido abovedadas generando los cauces que depositan los sedimentos y otros materiales arrastrados por las lluvias de invierno directamente al océano.y transformadas en ejes viales. 
Hacia el suroeste de Valparaíso se pueden identificar distintos niveles de terrazas que van desde los 20 a 60 metros de altura sobre el nivel del mar hasta alcanzar sobre los 450 de altura. En su conjunto los cerros concentran casi el 90\% de los habitantes de la ciudad, dando paso a un proceso de ocupación cuya expresión natural es el paisaje urbano y alrededor del 10\% de las actividades productoras de bienes y servicios.

\section{Evolución poblacional y urbana la ciudad}

El desarrollo histórico señala que la ciudad fue primero una aldea que crece muy lentamente durante el período colonial, y tal como la mayoría de los puertos de la América Hispana, no se fundó y trazó oficialmente, sino que se desarrolló de manera espontánea. La primera manifestación urbana se concreta en 1536 en la estrecha área plana del puerto, llamada caleta el Quintil.

Entre los siglos XVI al XVIII sólo se conserva la traza original de su planta a causa de los efectos de terremotos y maremotos que suelen afectar la región central el país. Tres son las funciones que se destacan en la dinámica inicial de la ciudad: las instalaciones de la actividad portuaria, las fortificaciones que la transforman en una plaza militar, y las fundaciones religiosas. En efecto, a pesar de la escasa población de la ciudad durante el siglo XVII, se fundaron los conventos de los franciscanos y jesuitas.

Lo anterior indica que la actividad del Valparaíso colonial fue relativamente pobre. Sin embargo, esta situación inicial cambia a partir de 1559 cuando se inicia la construcción de una capilla en el lugar donde en la actualidad se encuentra la Iglesia de la Matriz. En su entorno inmediato surgen bodegas y casas. Sobre el cerro Cordillera se alza el Castillo San José, fortificación construida por los españoles como protección de la Bahía y de la población, como también los que se levantan posteriormente en los cerros Artillería, Concepción y Barón (Sánchez, A. 2003).

A comienzos del siglo xix, Valparaíso alcanzó un mayor protagonismo y notoriedad pública al transformarse en la ciudad más dinámica del país, su población aumento casi tres veces en sesenta años. El puerto pasó a ser el principal centro económico del país y un importante enclave dentro de las rutas que comunicaban Europa con la costa del Océano Pacífico a través del Cabo de Hornos, coincidiendo con el inicio de una política de apertura internacional con ventajosas condiciones para los extranjeros que se instalasen en el país. En 1840, el camino entre Valparaíso y Santiago era la vía más impor- 
tante de Chile por allí se trasladaban los productos para el consumo interno y también los destinados al comercio internacional. En 1842 se concentra en la ciudad la función administrativa a nivel regional, al crearse la Provincia de Valparaíso. Ese mismo año se construyen los Almacenes Fiscales y en 1850 se inauguró la Bolsa Comercial. Este auge comercial coincide con la creación de los dos primeros bancos privados en el país, uno de los cuales estaba localizado en Valparaíso (1855).

Hacia la segunda mitad del siglo XIX, Valparaíso se convierte también en un gran punto de entrada de la inmigración, atrayendo población de diversos orígenes, donde destacan: ingleses, alemanes, franceses, italianos, yugoslavos y norteamericanos, que se establecieron en Valparaíso aportando una nueva particularidad al crecimiento de la ciudad pues eran comerciantes y profesionales liberales. El nuevo espíritu de empresa que caracterizó a algunos de estos emigrantes hizo que su campo de acción fuera el ámbito urbano. Muchos de ellos lograron importantes fortunas, que combinaron con intereses en el sector de comercio, las finanzas y la minería. En el caso de la mayor presencia de los marinos ingleses, a partir del año 1800, se empieza a notar una marcada influencia británica en el paisaje urbano de algunos barrios y en el nombre de sus calles. También editaban sus periódicos en su propio idioma. La colonia residente en el puerto, con gran esfuerzo, iniciativa fue incorporándose primero al comercio y luego a las actividades agrícolas y mineras. Otro ejemplo a destacar, durante la década de 1860 el $38 \%$ de los franceses que llegaron al país se domiciliaron en Valparaíso (Le Dantec, F. 1991).

Desde mediados del siglo xix hasta la mitad del siglo xx, Valparaíso fue el eje de la capital económica del país, concentrando el mayor movimiento monetario, la mayoría de las sedes de las nuevas sociedades mineras e industriales, oficina de ferrocarriles, compañías mercantiles y aseguradoras (foto 1). En este momento de prosperidad se vio interrumpido por el terremoto de 1906, que la destruye en gran parte, especialmente, en el sector Almendral. Unos años más tarde la apertura del canal de Panamá (1914), sería también un duro revés para continuar el sostenido auge y desarrollo del puerto, el tráfico marítimo disminuyó, provocando un decaimiento de la actividad económica y financiera de la ciudad. La crisis económica de 1929, cede paso a la emigración de las industrias hacia Santiago, dando inicio a un período de depresión que ha sido muy difícil de revertir (tabla 1). El siglo xx, estuvo marcado por diversos acontecimientos de carácter político, social y económico que afectaron la convivencia nacional, junto con los fenómenos naturales que con frecuencia han golpeado a la ciudad. 


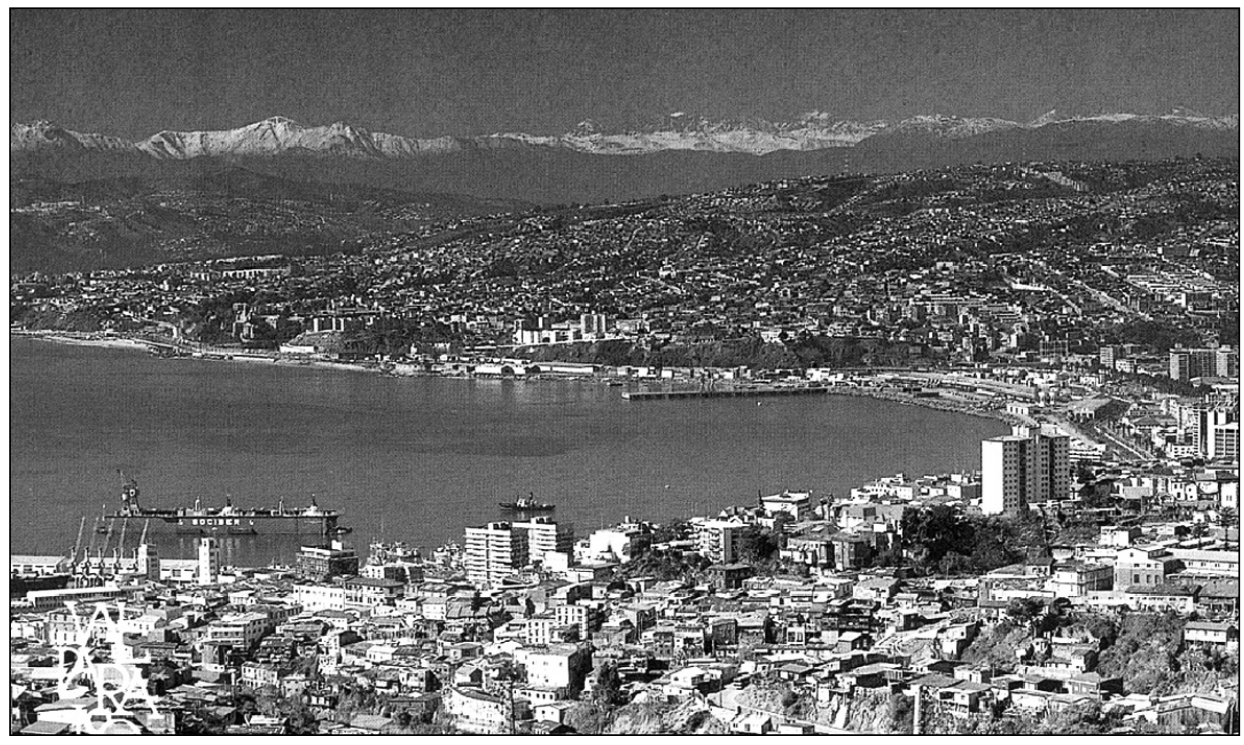

Foto 1. Ciudad de Valparaíso

TABLA 1

CRECIMIENTO INTERCENSAL DE LA CIUDAD DE VALPARAÍSO

\begin{tabular}{ccccccc}
\hline Año & 1865 & 1875 & 1885 & 1895 & 1907 & 1920 \\
\hline Población & 70.438 & 97.737 & 104.952 & 122.447 & 162.447 & 182.422 \\
\hline Año & 1930 & 1940 & 1952 & 1960 & 1970 & 1982 \\
\hline Población & 193.205 & 209.945 & 218.829 & 252.865 & 250.385 & 265.313 \\
\hline
\end{tabular}

Fuente: Bodini, H.: "Geografía de Chile", IGM, 1982, p. 79.

Como consecuencia de lo anterior, numerosas edificaciones del área céntrica destinadas a uso residencial de la ciudad fueron abandonadas y la ciudad atravesó por un duro período de desvalorización. Frente a este duro dilema la responsabilidad del Estado a través de sus organismos de administración y de ejecución, es cuidar el espacio público y mantenerlo en condiciones mínimas de uso y ponerlo permanentemente en valor de modo de incentivar al privado por otro lado a intervenir la propiedad privada de modo de evitar su envejecimiento incentivando su renovación urbana. 
En este paisaje urbano tan particular la ciudad creció hacia los cerros que rodean la bahía, situación que se manifiesta con particularidad en las viviendas erigidas sobre sus laderas. Las construcciones se encaramaron sobre ellos dando lugar a una morfología característica sólo de esta ciudad. Las soluciones estructurales ingeniosas y creativas están dadas por los particulares estilos según el grado de adaptación de las construcciones a la pendiente y la orientación al paisaje marítimo. Así los diversos pasajes, escaleras y ascensores para transitar y comunicar el plan con el cerro constituyen el símbolo de mayor identidad de Valparaíso. En este naciente paisaje urbano tan propio de Valparaíso, la comunicación entre plan y cerro fue siempre difícil, la diferencia de pendiente (hasta $63,5^{\circ}$ en el caso del ascensor Lecheros) dificultaba a la población su desplazamiento diario. La solución fue la instalación de los ascensores en distintos puntos de la ciudad, entre 1882 a 1930. Su creador fue el ingeniero Liborio Breba. Hoy día los ascensores junto con acortar camino ente plan y cerro "acortan" contribuyen a diversificar y enriquecer los recorridos turísticos por Valparaíso (foto 2).

Como su desarrollo urbano se caracteriza por la falta de espacio, las autoridades han realizado permanentes esfuerzos de relleno en espacios que inicialmente formaban parte del mar, en segundo término el proceso de poblamiento de los cerros ha sido sacrificando la cobertura vegetacional, configurando una

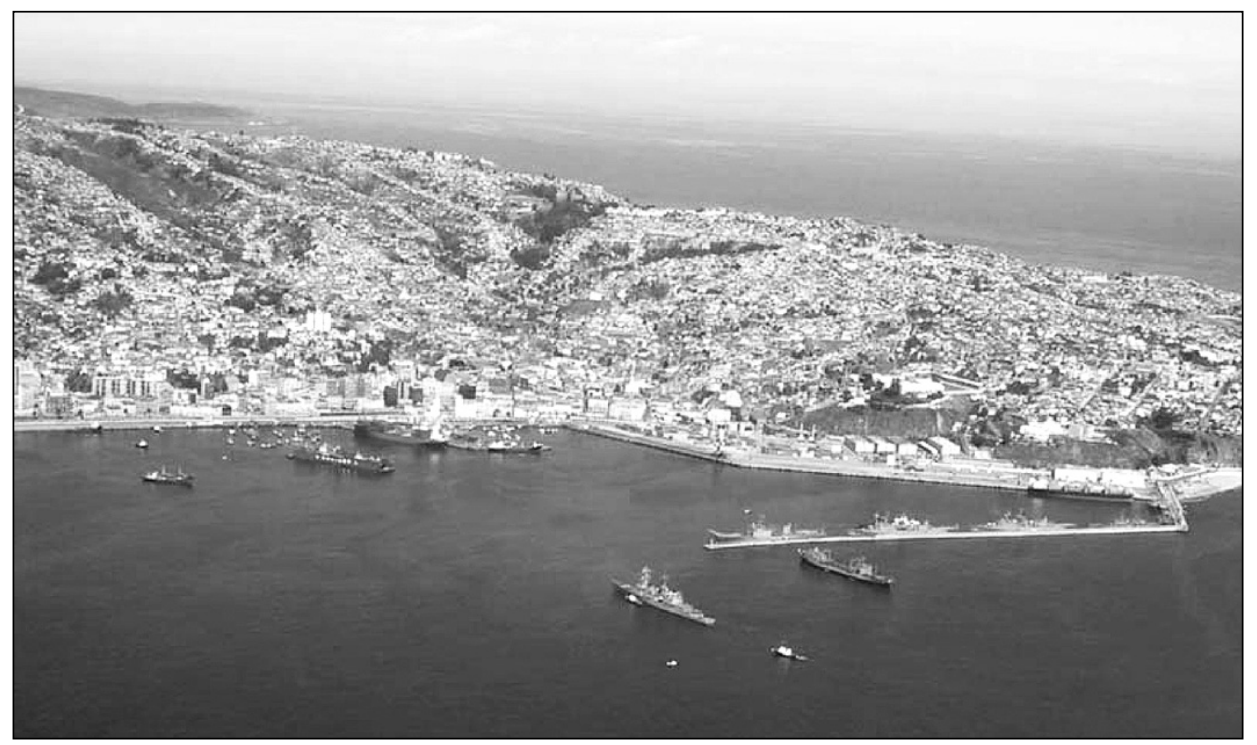

Fото 2. El puerto de Valparaíso

Estudios Geográficos, Vol. LXX, 266, pp. 269-293, enero-junio 2009 ISSN: 0014-1496, eISSN: 1988-8546, doi: 10.3989/estgeogr.0445 
paisaje urbano muy singular. Espacialmente la ciudad de encuentra conurbada con Viña del Mar, Concón, Quilpue y Villa Alemana y recibe el nombre de Gran Valparaíso. La ciudad es también sede del poder legislativo de la nación. Alberga al gobierno regional y sirve de sustento a la actividad portuaria a través de la prestación de servicios (tabla 2).

TABLA 2

POBLACIÓN URBANA Y RURAL POR SEXOS, 2002

\begin{tabular}{lcrr}
\hline \multicolumn{1}{c}{ División Administrativa } & Población & Hombres & Mujeres \\
\hline Valparaíso & 275.982 & 135.217 & 140.765 \\
Urbana & 275.141 & 134.757 & 140.384 \\
Rural & 841 & 460 & 381 \\
\hline
\end{tabular}

Fuente: INE, 2002.

La ciudad aporta el apoyo necesario a la actividad portuaria con el desarrollo de una completa infraestructura vial, El puerto de Valparaíso ha ido modernizándose en el tiempo, tiene una historia muy rica en ese sentido pero luego de que la ley 19.542 (Licitación de puertos EMPORCHI a privados) fuera publicada en 1997 ha dado un importante paso a la competitividad, siendo como el puerto más moderno del país. Desde su privatización el puerto Valparaíso ha registrado un fuerte crecimiento en la transferencia de carga, lo cual hace necesario su expansión física, mediante áreas de respaldo para sus actividades. Los datos mostrados por la empresa indican que mientras el año 2000 el puerto mantenía una participación del $41 \%$ en el movimiento de carga general de la región, el 2007 Valparaíso concentró el 56\%.

EL PROCESO DE NOMINACIÓN DE VALPARAíSO COMO PATRIMONIO DE HUMANIDAD. ALCANCES Y PROYECCIONES

La ciudad de Valparaíso posee uno de los títulos más importantes que alguna urbe pueda acceder en cuanto al reconocimiento de sus bienes culturales, fue declarada el 2 de Julio de 2003 como Patrimonio de la Humanidad por la Organización de las Naciones Unidas para la Educación, la Ciencia y la Cultura (UNESCO), luego de ser nombrada Capital Cultural de Chile. 
Sin embargo, resulta interesante analizar como este proceso de postulación de la ciudad, iniciado en el seno académico, ha generado cambios fundamentales en la percepción ciudadana y en la dimensión político-económicacultural-educacional y turística, visualizándose que la conservación y puesta en valor del patrimonio cultural de esta singular ciudad-puerto, constituye una gran fortaleza y fuente de desarrollo de la ciudad y bienestar para sus habitantes.

\section{El ámbito académico}

En el ámbito académico, destaca la Universidad de Chile, institución abocada históricamente desde las primeras clases de arquitectura a mediados de siglo XIX, al cultivo del acervo cultural chileno y con liderazgo en la investigación de la historia de la arquitectura chilena. Dentro de los prestigiados arquitectos investigadores del siglo xx, la arquitecto académico Myriam Waisberg Izacson (QEPD) lidera la investigación científica en el campo de la historia de la arquitectura de Valparaíso cimentando las bases para la preservación del patrimonio arquitectónico de esta ciudad: "Entre la variada producción del Centro de Investigación de Valparaíso, adquiere especial importancia el inicio de los trabajos de investigación en la región (Waisberg I, 2000) asegurando con esta acción, la continuidad de las investigaciones que se desarrollan en la nueva sede de Valparaíso a partir del año 1957.

La sucesora Universidad de Valparaíso, aporta a la formación de profesionales arquitectos involucrados en el Patrimonio, quienes despliegan la aplicación de metodologías de investigación científica en forma continua y silenciosa, lo que permitirá acumular una cantidad considerable de estudios generadores de nuevos conocimientos sobre aspectos arquitectónicos y urbanos de la ciudad, que irán conformando un gran banco de datos confiables que jugará junto con los aportes de otras Casa de Estudios Superiores de la región, un rol primordial en la fundamentación de los valores singulares y universales de la ciudad, como base de la postulación ante UNESCO.

\section{El ámbito político-público}

Históricamente la ciudad de Valparaíso, ha sido reconocida como primer puerto del país, desplegando su mayor desarrollo marítimo-portuario durante la segunda mitad del siglo xIX, sin embargo, a partir de las primeras décadas 
del siglo xx la ciudad comienza a decaer, a la vez que Santiago se convierte en un polo de atracción cada vez mas poderoso, emigrando en forma paulatina las industrias hacia la capital y generándose un progresivo aumento de la cesantía, situación que conlleva a un decaimiento y deterioro de la ciudadpuerto que se mantiene durante todo ese siglo.

A fines de siglo, obras como la instalación del Congreso Nacional en Valparaíso y programas de gobierno que incluyen estrategias de desarrollo para la región, planes de desarrollo urbano para el área metropolitana de Valparaíso, los corredores internacionales andino-portuarios, el desarrollo del puerto, la construcción del camino de la Pólvora, la remodelación de los ejes transversales urbanos constituyen valiosas iniciativas de los gobiernos de turno para revertir el deterioro y entregar un nuevo impulso para el desarrollo a Valparaíso.

En este marco, el proceso de postulación y la nominación de Valparaíso como Patrimonio de la Humanidad vienen a abrir una novedosa perspectiva de desarrollo cultural de la ciudad que se complementa con un fuerte impulso que le otorgan las Universidades que se concentran en la región.

\section{El ámbito legal}

Por muchos años, el marco legal del patrimonio en Chile, estuvo bajo la tuición de la Ley 17288 de Monumentos Nacionales del Ministerio de Educación que rige desde el año 1970 y cuyas primeras normas se remontan al año 1925 siendo declarados el Fuerte Esmeralda como primer monumento histórico de Valparaíso y el entorno de la Iglesia La Matriz en 1971 como primera zona típica según Decretos del Ministerio de Educación No 1510 del 26 de marzo de 1938 y 2412 del 6 de octubre 1971 respectivamente.

En el año 1976 se introduce un cambio fundamental en la legislación referida a la protección del Patrimonio arquitectónico y urbano al incorporarse en el DS 458 del año 1976 Ley General de Urbanismo y Construcciones una norma directamente relacionada con la planificación territorial que permite la identificación, protección e incorporación de inmuebles y zonas de conservación histórica a los planes reguladores, permitiendo así un reconocimiento, tratamiento integrado y protección legal de los conjuntos y áreas ligadas a la historia, la geotopografía, y los valores urbanos y arquitectónicos, desde una visión de la planificación urbana. Valparaíso será pionero en la aplicación de esta norma, al identificar e incorporar el Área Histórica del Puerto al Plan Regulador Comunal en el año 1997. 


\section{El ámbito ciudadano}

En el marco de los 200 Años del Municipio de Valparaíso 1791-1991 y como una actividad extraordinaria, para obtener una visión integral de las diversas problemáticas de la ciudad y visualizar vías de desarrollo, el Municipio de Valparaíso en el año 1991 convoca a un Cabildo ciudadano que marcará un hito en los lineamientos que seguirán en la protección del Patrimonio de la ciudad. Es así que como respuesta a la voluntad ciudadana expresada en el área de cultura de dicho Cabildo y las evaluaciones de los compromisos adquiridos en el año 1993, la autoridad comunal, en el año 1994 da inicio a los estudios tendientes a la protección del patrimonio arquitectónico-urbano a través de los instrumentos de planificación territorial, desarrollándose en el seno municipal los primeros Estudios Seccionales a nivel del país: Preservación de Inmuebles y Zonas de Conservación Histórica y Preservación de Vistas desde los Paseos Miradores. El área del Puerto constituye así dentro del escenario de la cuenca marítima, la primera etapa prioritaria con alto valor histórico, arquitectónico y urbano, reconocida y resguardada a través de una ordenanza, y de la cual se adquiere el compromiso de poner en valor (foto 3 ).

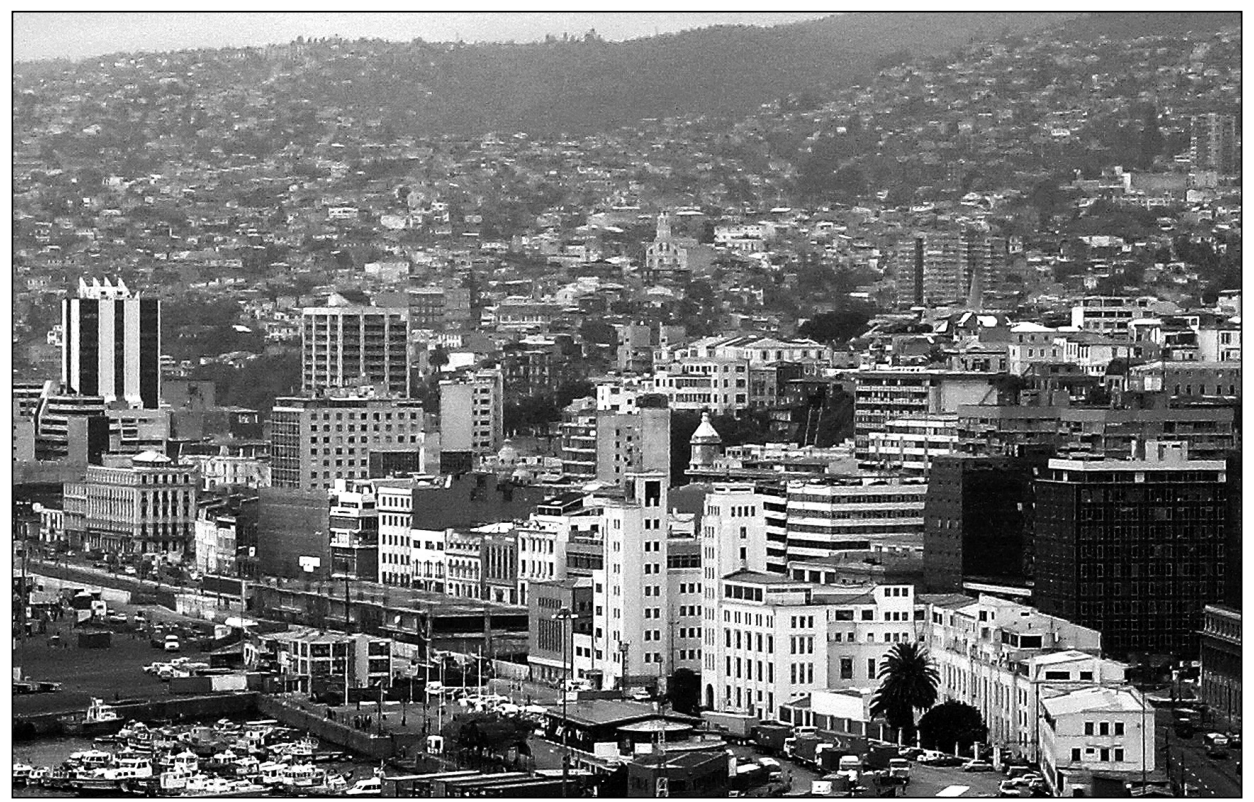

Fото 3. Vista panorámica del área histórica

Estudios Geográficos, Vol. LXX, 266, pp. 269-293, enero-junio 2009 ISSN: 0014-1496, eISSN: 1988-8546, doi: 10.3989/estgeogr.0445 
No obstante el interés ciudadano, ya manifestado en ese período, se hace evidente un desconocimiento generalizado respecto a los conceptos y alcances de la valorización del patrimonio de la ciudad, no sólo de parte de la comunidad sino de los entes profesionales, políticos y medios de comunicación, que demandan fundamentos sobre el tema. Esto lo demuestran los cuatro años que transcurren hasta la aprobación de ambos estudios y su incorporación finalmente al Plan Regulador Comunal a fines del año 1997, publicados en los Diarios Oficiales del 4 y 10 de octubre respectivamente.

Este período de discusión y difusión ante la opinión pública, permitirá la generación de una plataforma base de conocimiento que contribuirá a la comprensión paulatina de que la conservación y puesta en valor del Patrimonio cultural de Valparaíso constituirá un agente de desarrollo para la ciudad.

Es necesario destacar que Valparaíso se transforma una vez mas en un referente que hace público un tema complejo y universal como es la valorización del Patrimonio, los rasgos culturales identitarios, las raíces, la memoria colectiva, las referencias y las proyecciones al futuro, situación que irradiará rápidamente a la región, estimulando a las diversas comunas de su juridicción a la identificación y protección de su propio patrimonio tangible e inmaterial.

\section{LA POSTULACIÓN ANTE UNESCO}

Casi en forma simultánea al reconocimiento y protección del Área Histórica del Puerto, ocurrida a fines del año 1997, en los primeros meses del año 1998, la Directora de Bibliotecas Archivos y Museos (DIBAM), presenta ante el Concejo Municipal y su Alcalde la propuesta de postular los ascensores urbanos de Valparaíso ante la UNESCO para ser inscritos en la Lista del Patrimonio Mundial, ante lo cual el Municipio con la experiencia acumulada, decide postular el Área Histórica del Puerto, protegida de acuerdo al Plano Seccional recién aprobado.

Cabe señalar que la iniciativa de postular a Valparaíso como Patrimonio de la Humanidad ante UNESCO ya había sido lanzada desde el ámbito académico como resultado de las conclusiones de las V Jornadas de Preservación Arquitectónicas-Urbana. Tercer Encuentro de Especialistas Americanos, convocada por la Universidad de Valparaíso en el año 1995.

De esta manera aún siendo una compromiso del estado chileno, el proceso de postulación del Área Histórica de Valparaíso como Sitio del Patrimonio Mundial ante UNESCO es iniciado por parte de la I. Municipalidad de Valparaíso, la que adquiere protagonismo al asumir el liderazgo, convocar y coor- 
dinar a todos los actores de la ciudad, los habitantes, las universidades, los organismos públicos y privados, los medios de comunicación y los agentes culturales, haciéndoles un llamado a asumir el compromiso de participación en el proceso, avizorándose así una dinámica de la ciudad frente a este nuevo tema que representa una esperanza para el mejoramiento de la ciudad, el desarrollo cultural y la calidad de vida de sus habitantes, sin embargo se debe reconocer que esta nueva visión de desarrollo, va acompañada de cierto escepticismo respecto a lograr la nominación, reconociendo las debilidades, problemas urbanos y carencia de gestión en este tema aún reciente que enfrenta la ciudad.

La Unidad Técnica de Patrimonio creada en el año 1998 en el seno municipal realizará una labor inédita al interior del Municipio, que escapa a todas las tareas habituales que en él se desarrollaban hasta ese momento asumiendo la responsabilidad de confeccionar el primer expediente de postulación, en alianza con la Universidad de Valparaíso, coordinando la participación de la comunidad, universidades, organismos públicos y privados y actores culturales. Junto a lo anterior realiza una acción de difusión técnica del tema en diferentes niveles ciudadanos y educacionales, participando en exposiciones, Jornadas y Congresos.

En ese período, la ciudad es constantemente visitada por expertos de América y Europa entre los que destacan el ecuatoriano Hernán Crespo Toral y el alemán Berndt von Droste quienes reconocen los valores patrimoniales de Valparaíso, pero que sin embargo, haciendo alusión a las Cartas Internacionales." La conservación de las poblaciones o áreas urbanas históricas sólo puede ser eficaz si se integra en una política coherente de desarrollo económico y social, y si es tomada en consideración en el planeamiento territorial y urbanístico a todos los niveles" (Doc. 5/1987) advierten el necesario compromiso y gestión integral del Estado Chileno sobre el bien que se postula ante UNESCO.

Es preciso decir que hasta entonces a nivel americano habían sido ya declaradas ciudades con sus centros históricos de impronta colonial y ajustadas a las leyes de Indias, por lo cual el reconocimiento de una ciudad puerto como Valparaíso, con marcadas influencias del cambio socio económico-cultural del siglo XIX constituía un desafío mayor. Por otra parte a nivel nacional, había sido inscrito en la Lista del Patrimonio Mundial el Parque Nacional Rapa Nui de Isla de Pascua en 1995 y desde 1998 se había iniciado el proceso de postulación de catorce iglesias de Chiloé, ambos sitios con experiencias en categorías distintas a la postulación de Valparaíso.

Ese mismo año, se establece el Consejo Regional de Monumentos Nacionales en Valparaíso, como una manera de descentralizar la tuición de ese orga- 
nismo sobre los Monumentos Nacionales, agilizar las autorizaciones y fiscalizar las intervenciones en edificios de valor patrimonial.

En esta etapa las autoridades locales y regionales luchan para que la ciudad de Valparaíso sea declarada capital de la Infraestructura Cultural del País, lo que se logra en el año 2000 representando un nuevo impulso en el tema. Los acontecimientos entorno a la cultura se aceleran y tres años mas tarde el Congreso Nacional aprueba la Ley 19891 que crea el Consejo Nacional de la Cultura y las Artes, la que es publicada en el Diario Oficial del 23 agosto 2003 y cuyo emplazamiento en el monumental edificio de ex Correos de Chile de Valparaíso, representa una nueva señal del gobierno de Chile para apoyar a Valparaíso en la valorización de su Patrimonio. Esta importante muestra de arquitectura moderna rehabilitada, según Permisos de Alteración y Rehabilitación 118 y 172 del 11 de abril y 19 de mayo del año 2005 para esta nueva función y con un emplazamiento privilegiado en la Plaza Sotomayor, espacio urbano teñido de historia, se convierte así en símbolo de un promisorio futuro de desarrollo de la cultura en la ciudad.

Como parte habitual de los procedimientos necesarios de cumplir de cualquier sitio que postula a ser reconocido como Patrimonio de la Humanidad, en enero del año 2000 La I. Municipalidad de Valparaíso recibe a la arquitecto argentina, María de las Nieves Arias Incollá, representante y designada por el Consejo Internacional de Monumentos y Sitios ICOMOS Internacional organismo técnico de carácter internacional, asesor de la UNESCO, para revisar el expediente y compenetrarse en terreno de los reales valores del área que se postula.

Involucrada totalmente en la temática, lo primero que expone la experta es que la declaración de UNESCO implica una gran responsabilidad del EstadoParte respecto a la puesta en valor del área. Luego de recorrer reiteradamente el área y la ciudad, el informe que emite establece que sin perjuicio de los valores universales sobresalientes que reconoce están presentes en la ciudad, como la característica de anfiteatro, la relación entre el soporte natural y el construido que genera una serie de características urbanas particulares como plazas, pasajes, escaleras y funiculares y una variada arquitectura representada por edificios y viviendas vernáculas estima que se hacen evidentes una serie de debilidades relacionadas con una gestión hasta ese momento casi inexistente ante un tema ciudadano que recién surge. Lo anterior referido fundamentalmente a la legislación en planificación territorial que ha permitido erigir una serie de edificaciones en altura que han alterado el paisaje propio de la ciudad y la necesidad de impulsar gestiones en el ámbito turístico, económico, social y educacional. Junto a lo anterior se recomienda reducir el área 
que se postula de manera de tener un mejor manejo de la misma y a la vez establecer en su entorno un área de amortiguación que mitigue posibles impactos negativos sobre la zona.

Ante esta situación y en esta etapa del proceso, el gobierno de Chile, suspende la tramitación del expediente técnico ante el Centro del Patrimonio Mundial, aunque valorando esta etapa "que evidenció el compromiso de la ciudad y del país con la conservación de los valores de Valparaíso y expuso los avances logrados hasta entonces... motivó profundos y renovados esfuerzos a favor del patrimonio de Valparaíso y contribuyó en alto grado a su difusión y protección" (Doc. 14/2001) y asume la responsabilidad que le compete, estableciendo una serie de medidas que impulsan gestiones tales como subsidios a la rehabilitación de inmuebles de valor patrimonial, planes de rehabilitación urbana, fondos concursables, subsidios a las actividades económicas directamente relacionadas con Patrimonio, circuitos turísticos e inventarios entre otras.

En este nuevo escenario, el año 2001 se implementa un Plan de Trabajo Segunda Fase, destinado a fortalecer la propuesta, conformando tres equipos de trabajo integrados por altos representantes del gobierno central regional y comunal así como de diversos organismos públicos y privados.

El nuevo expediente, reformulado en conjunto con el Consejo de Monumentos Nacionales, le incorpora al Área Histórica, una zona de amortiguación y agrega las diversas gestiones recientemente asumidas. En enero del año 2002 el nuevo expediente de postulación de Valparaíso como Sitio del Patrimonio Mundial es ingresado oficialmente por el Estado de Chile, a través del Ministerio de Relaciones Exteriores al Centro del Patrimonio Mundial de la UNESCO. En julio de ese año, ICOMOS Internacional, envía una experta, esta vez de Brasil, Adriana de Castro, en misión de evaluación de la postulación, quien consta los avances principalmente en cuanto a gestión sobre el área que se postula, emitiendo un informe favorable, con pequeñas recomendaciones. A principios de enero del 2003 la ciudad de Valparaíso recibe la visita oficial del Sr. Koichiro Matsuura Director General de la UNESCO.

\section{LA NOMINACIÓN}

Finalmente, el Comité del Patrimonio Mundial, en su XXVII sesión ordinaria del 2 de julio 2003 realizada en París Francia, resolvió favorablemente, por unanimidad, la inscripción de un sector del Área Histórica de la ciudad puerto de Valparaíso en la Lista del Patrimonio Mundial (figura 3). 

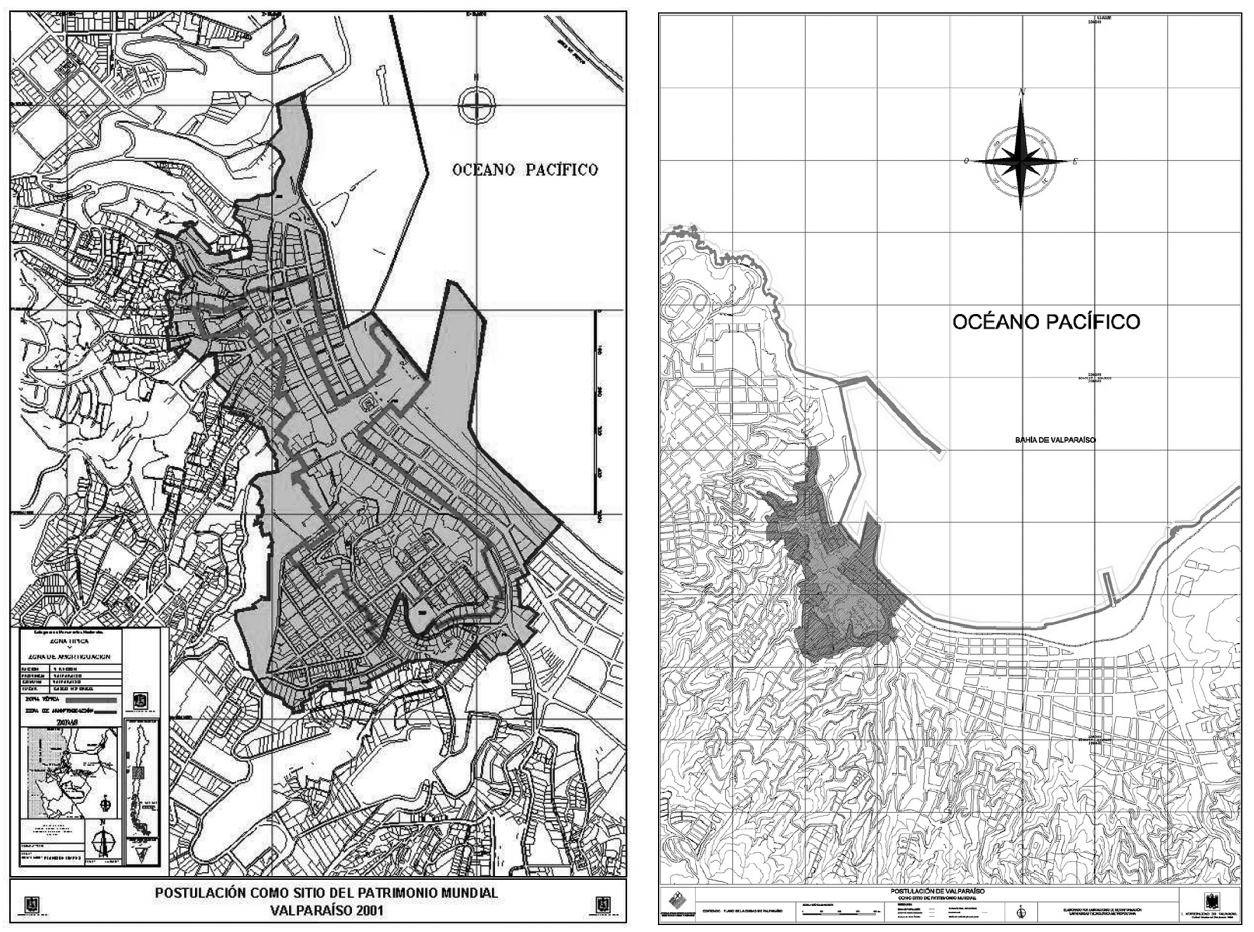

Fuente: Unidad Técnica de Patrimonio.

I. Municipalidad de Valparaíso.

Figura 3. Plano de área Unesco

El Sitio cumplió con el criterio iii de valor universal de bienes culturales "Es un testimonio único o por lo menos excepcional de una tradición cultural o de una civilización viva o desaparecida" y fundado en que "Valparaíso is an exceptional testimony to the early phase of globalisation in the late 19th century, when it became the leading merchant port on the sea routes of the Pacific coast of South America". ${ }^{1}$ XXVII sesión ordinaria del Comité del Patrimonio Mundial 2 de julio 2003 París Francia.

En dicha sesión el Comité resolvió además: Estimular al Estado Parte a continuar sus esfuerzos en orden a inventariar y proteger la infraestructura relacionada a los usos históricos del sector portuario y de los sistemas de transporte, desarrollar planes de manejo y conservación en toda el área marítimo-portuaria y clarificar con mayor precisión las normas y directrices en las áreas adyacentes a las zonas protegidas. 
A partir de esta fecha, se observa con mayor fuerza el desarrollo de una serie de iniciativas que venían ejecutándose en forma lenta y prudente, desde el nivel central, regional y comunal, que contemplan planes programas y proyectos que abarcan financiamientos e incentivos para la recuperación de inmuebles de valor patrimonial, ya sea a través de la restauración o rehabilitaciones para su reutilización o cambios de destinos. Asimismo las Universidades acentúan los estudios, seminarios, memorias, tesis y proyectos de títulos, teniendo como tema central la conservación del patrimonio arquitectónico y urbano.

La I. Municipalidad refuerza campañas urbanas de recuperación de fachadas y establece exenciones de derechos para las rehabilitaciones. Junto a lo anterior, organismos privados se aventuran en las primeras inversiones en edificios preexistentes, asumiendo el desafío de encontrar el justo equilibrio entre desarrollo enfrentado al siglo xxI y la preservación del patrimonio tanto arquitectónico como urbano. La comunidad acentúa el interés y valorización por lo propio, vislumbrándose el reconocimiento del patrimonio inmaterial y acrecentando su participación. Los medios de comunicación mantienen en forma permanente la información sobre la nominación y sus alcances.

En esa etapa del proceso, la Unidad Técnica de Patrimonio advierte la necesidad urgente de elaborar un Plan Estratégico de Desarrollo Patrimonial en el Área UNESCO entendiéndolo como un instrumento de gestión y planificación, cuyo objetivo fuera canalizar las gestiones a nivel central, regional y comunal tendientes a lograr una planificación integral del área, que concilie la conservación con el desarrollo, coordine la acción de los agentes públicos, privados y ciudadanos, permita la optimización de recursos y el monitoreo en el tiempo. El año 2005 se concreta el préstamo del Banco Interamericano de Desarrollo BID, desarrollándose una serie de estudios y proyectos tendientes al mejoramiento del Área Histórica, los cuales en la actualidad se encuentran en ejecución.

\section{CONCLUSIÓN: ALCANCES Y PROYECCIONES}

El proceso iniciado a nivel académico, logró fortalecerse involucrando las diversas voluntades y actores ciudadanos en el reconocimiento al Patrimonio cultural de Valparaíso como factor de desarrollo no tan sólo comunal sino en la intercomuna y la región, entendiéndolo "como un recurso de alto valor social, cultural, histórico, económico y paisajístico, sobre el cual fundar integralmente los planes, programas y proyectos que se generen con vistas a establecer un modelo concreto de desarrollo sustentable" (Doc. 9/2005). 
Durante todo el desarrollo de la postulación, el tema patrimonial se convierte en un elemento integrador de la ciudadanía de Valparaíso, que valora la iniciativa y apoya incondicionalmente el proceso, el que se convierte en un agente para impulsar e incentivar en forma creciente la formación de organizaciones sociales civiles que velan y luchan por la protección de los bienes de la ciudad, experimentándose un compromiso ciudadano cada vez mayor.

A nivel municipal, se acentúa la protección del patrimonio arquitectónico y urbano a través de la planificación territorial, reconociéndose en los años 2004 y 2005 la totalidad de anfiteatro como una gran zona de conservación histórica, incorporada al Plan Regulador Comunal, que involucra además el sector Almendral y los cerros Placeres y Esperanza por el oriente y el peñón de Playa Ancha por el sector poniente de la ciudad, incluyendo además el Borde Costero, proyecto no exento de polémica.

El préstamo del Banco Interamericano de Desarrollo BID al Estado de Chile, considera financiamientos destinados a planes programas y proyectos para el mejoramiento del Área Histórica así como para la puesta en valor de edificios relevantes. También se llama a licitación el Plan Director de Gestión Patrimonial del Área Histórica, cuya primera etapa se encuentra actualmente en desarrollo.

Hoy Valparaíso como ciudad puerto, Patrimonio de la Humanidad se proyecta y enfrenta grandes y urgentes desafíos, como una necesaria planificación integral, que concilie la preservación de su Patrimonio arquitectónico-urbano con las nuevas construcciones e intervenciones sobre las preexistentes, la densificación y recuperación arquitectónica, urbana y social del área Histórica, un manejo prudente de la explotación turística, una relación armónica y equilibrio justo entre la ciudad y su borde costero pieza fundamental de su desarrollo y por sobre todo una participación ciudadana real y permanente como garante de sustentabilidad de un proceso permanente y dinámico de puesta en valor del Paisaje Cultural de esta ciudad.

Recibido: 08/09/2009

Aceptado: 03/03/2009

\section{BibLiografía}

Bodini, H.(1982): "Geografía de Chile”, IGM, Santiago de Chile,1982, p. 79.

Consejo de Monumentos Nacionales (2001): "Postulación de Valparaíso como sitio del Patrimonio Mundial". I. Municipalidad de Valparaíso. 
Dueñas, B.y Miguel-Opazo,L.: "Estudio Seccional Preservación de Vistas desde Paseos Miradores. I. Municipalidad de Valparaíso 1993-1997.

Hidalgo, R. (2005): "Puerto Abierto ¿ciudad cerrada?, transformaciones socio-espaciales en la estructura urbana del Área Metropolitana de Valparaíso". En Revista Geográfica de Valparaíso. Número 36, páginas 189-2006. Valparaíso, Chile.

Jiménez, V. C. y Ferrada, A. M.: "Estudio Seccional Preservación de Inmuebles y Zonas de Conservación Histórica. I. Municipalidad de Valparaíso 1993-1997.

Le Dantec, F. (1991): "Historia y leyendas de Valparaíso". Ediciones Universitarias de Valparaíso, páginas 191-195. Valparaíso, Chile.

Martínez Corbella, C.: "La sede de Valparaíso de la Universidad de Chile. La Reforma Universitaria 1968-1973 Valparaíso 2002.

Salinas, R. (1967): "Condiciones Naturales y Humanas en la formación del Área Metropolitana de Valparaíso". En Revista Geográfica de Valparaíso, Vol I, No 1, páginas 1-31. Valparaíso, Chile.

Sánchez, A. (2003): "Geografía de Chile” Editorial Bibliográfica Internacional, páginas 314 a 322. Santiago de Chile.

Sánchez, A. y Morales, R. (2003): Las Regiones de Chile”. Editorial Universitaria, cuarta edición, páginas 86-106, Santiago de Chile.

Vásquez, N. (1999): "Cartografía Histórica de Valparaíso" Editoriales Universitarias de Valparaíso, Valparaíso, Chile ${ }^{3}$.

Waisberg, I. M. I.: "El Centro de Investigación de Valparaíso" En Cuadernos Facultad de Arquitectura Mayo 2000

\section{DOCUMENTOS}

1. Convención del Patrimonio Mundial, Cultural y Natural aprobada por UNESCO en 1972 y ratificada por Chile en 1980.

2. Guía Operativa para la implementación de la Convención del Patrimonio Mundial.

3. Carta-Documentos Internacionales sobre Conservación, Preservación y Tratamiento del Patrimonio Cultural Mundial. Recopilación Área de Estudios y Normativa. Unidad Técnica de Patrimonio I. Municipalidad de Valparaíso 2001.

4. Carta de Nara sobre Autenticidad. Nara, Japón. 1994.

5. Carta para la Conservación de Ciudades y Áreas Históricas. Washington 1987.

6. Actas de V Jornadas Chilenas de Preservación Arquitectónica y Urbana. Tercer Encuentro de Especialistas Americanos".Facultad de Arquitectura Universidad de Valparaíso Chile. 1995.

7. Coloquio El Patrimonio Arquitectónico de Valparaíso en las Artes. Facultad de Arquitectura Universidad de Valparaíso. Valparaíso 1998. 
8. Cabildo para el desarrollo de Valparaíso. En el marco de los 200 años Municipio de Valparaíso 1791-1993.

9. Patrimonio Valparaíso: Estado de avance y Proyecciones Unidad Técnica de Patrimonio I. Municipalidad de Valparaíso 2005.

10. Monumentos Nacionales de Chile Dirección de Arquitectura MOP-Consejo de Monumentos Nacionales.

11. Primer Expediente Técnico de Postulación Valparaíso Patrimonio de la Humanidad Unidad Técnica de Patrimonio I. Municipalidad de Valparaíso 2000.

12. Segundo Expediente Técnico de Postulación Valparaíso Patrimonio de la Humanidad.

13. Postulación de Valparaíso como Sitio del Patrimonio Mundial UNESCO. Cuadernos del Consejo de Monumentos Nacionales. Segunda Serie No 70. Santiago 2004.

14. Resumen Informativo del Consejo de Monumentos Nacionales e I. Municipalidad de Valparaíso. Diciembre 2001.

15. Programa de Desarrollo de Valparaíso 1995. Discurso del Presidente de Chile don Eduardo Frei Ruiz Tagle.

16. Ley 19891 fue publicada en el D.O. del 23 agosto 2003.

17. D.O del 16 de febrero 2004.

18. D.O del 21 de marzo 2005.

19. D.O del 12 de noviembre 2007

20. D.O del 18 de marzo 2005.

21. Permisos de Alteración y Rehabilitación 118 y 172 del 11 de abril y 19 de mayo del año 2005.

22. Ley 19891 fue publicada en el D.O. del 23 agosto 2003.

\section{RESUMEN}

Valparaíso fue declarado Patrimonio de la Humanidad en el año 2003, por su importancia histórica, belleza natural y una arquitectura única. Este artículo analiza los detalles de este proceso iniciado en 1998 y que culminó con el reconocimiento de UNESCO.

La importancia de esta decisión beneficia también a la población de la ciudad, por cuanto se preserva y propende a la conservación del valor cultural propio de la ciudad. Este proceso tiene un segundo aspecto positivo, en términos de los cambios en materia de políticas, sociales, culturales y económicos, como en caso del turismo para que incluyan el valor de la ciudad en su propio desarrollo.

PALAbras Clave: Valparaíso; Unesco; Alcances; Resultados.

\section{Abstract}

Valparaíso was declared a World Heritage Site in 2003, thanks to its historical importance, natural beauty (large number of hills surrounding a picturesque harbor), and unique architecture (particularly, a mix of 19th century styles of housing). In essence, 
this paper focuses on a detailed and documented exposition of the process begun in 1998 that allowed the seaport city of Valparaíso to be listed as UNESCO World Heritage in 2003.

The importance of this process lies on its positive impact amongst citizens and the rise of an increasing awareness regarding the preservation and conservation of their cultural endowment, both tangible and intangible. The process has positively effected change in political, social, legal, cultural, economic, and tourism-centered areas involved in the preservation of the city`s heritage, its potential and development.

KEY WORDS: Valparaíso; Unesco; Reach; Outcomes.

\section{RÉSUMÉ}

Valparaíso a été déclaré Patrimoine de l'Humanité en 2003, par son importance historique, sa beauté naturelle et son architecture unique. Cet article analyse les détails de ce processus qui a débuté en 1998 et a culminé avec la reconnaissance de l'UNESCO. Limportance de cette décision fait aussi du bien aux habitants de Valparaíso, puisqu'on préserve et tend à conserver la valeur culturelle propre à la ville. Ce processus a un deuxième aspect positif, du point de vue des changements politiques, sociaux, culturels et économiques ainsi qu'en matière de tourisme, afin d'inclure la valeur de la ville dans son propre développement.

MoTS CLÉS: Valparaíso; UNESCO; portée; résultats. 